\title{
Research on the Risk Prevention of Government Purchase of Public Services
}

\author{
Chen Yanfang ${ }^{1} \&$ Geng Hong ${ }^{1}$ \\ ${ }^{1}$ College of Economics and Administration, Nanjing University of Aeronautics and Astronautics, China \\ Correspondence: Chen Yanfang, College of Economics and Administration, Nanjing University of Aeronautics \\ and Astronautics, Nanjing 210016, China. E-mail: chenyanfang326@163.com
}

Received: November 23, 2017

Accepted: December 28, 2017

Online Published: January 15, 2018

doi:10.5539/ijbm.v13n2p187

URL: https://doi.org/10.5539/ijbm.v13n2p187

\begin{abstract}
How to prevent the risk has become the proper meaning of perfecting the government purchase of public service system arrangement. According to the basic process: public resources investment - configuration and conversion - output and feedback process, the paper analyzes the main factors influencing the government purchase of public service risk, and puts forward the risk prevention countermeasures. That is, reasonable guidance of private capital into the field of public services, improvement of government management, promotion of social autonomy, market allocation function, and convergence with supporting reforms.
\end{abstract}

Keywords: government purchase, public service, risk factor, risk prevention

\section{Introduction}

Based on the public service administrative monopoly supply model to reflect the economic cost, social benefits and public value, in the new public management movement background, our country western countries in practice, changed the public service supply system, push government purchase of public service system. In the deployment of the government, the government purchase of public services into the normal development, improvement in the quality of public services, ease the financial pressure, improve the image of the government achieved remarkable results. However, with the promotion of the system, many problems also follow. During the process of government purchase of public services, a lot of purchasing chaos has led to serious waste of public resources, lack of publicity, public discontent. Institutional arrangements did not achieve the desired results, the implementation of the system in the course of the abnormal situation led to people's rational thinking. Although the government purchase of public services through market allocation to break the monopoly of public services supply and public resources, but as forced a new supply system reform mechanism, in practice and the lack of understanding of the situation, groping forward way often lies the great uncertainty of risk. At present, there is a certain relationship between the exposed problems and the lack of awareness of institutional arrangements, risk prevention and control is not in place. Therefore, in order to further improve the performance of the system arrangement and reduce the risk of system operation, it is necessary to further explore the risk of government procurement of public services, and put forward effective risk prevention countermeasures.

\section{The Motivation of Government Purchase of Public Services}

2.1 Based on the Perspective of Purchase Object: to Improve the Supply of Public Services and Optimize the Allocation of Public Resources

At present, the weakness of public service and the imbalance of supply have become the short board that restricts the social transformation and upgrading. First, public resources are insufficient and public goods are in short supply. First, public resources are insufficient and public goods are in short supply. According to statistics, in 2015 the general public service expenditure accounted for only 7.7\% of the national fiscal expenditure, while the United States in about $20 \%$, the UK between $35 \%-43 \%$, and Australia between $36 \%-43 \%$. Secondly, the allocation of public resources is not balanced, and there is a significant difference in public resources in the region, urban and rural areas and different service types. Under the new social background, the transformation and upgrading of consumption structure, the urbanization of population and the dominant pattern of service industry make the demand for public services grow rapidly and the pressure of public service supply increases significantly. The contradiction between supply and demand of public resources is further prominent. Thirdly, the 
waste of public resources is serious, and the public resources cannot serve the people. The simple administrative leading supply mode makes the public service lack of effective system guarantee in quantity, quality, attitude and supervision guarantee. In view of the above situation, the government proposes to purchase public services to the social forces, through adjusting the structure, opening the market, introducing social capital, the society can afford as much as possible to the community to undertake. The government should return to the role of supervisor, optimize the allocation of public resources by standardizing public resource trading platform, strengthening market regulation and maintaining market order.

\subsection{Based on the Perspective of Buyers: Seeking for Legal Support and Promoting the Transformation of Government Functions}

The reform of public service supply system and the increase of effective supply of public services are the necessary requirements of the development of public administration, as well as an important measure to promote the transformation of government functions and enhance the credibility of the government. First of all, the innovation of public service system arrangement, committed to the allocation of resources and public preferences to match, reflects the shift of the focus of government functions to public services, public service awareness and service-oriented government building determination. Secondly, the introduction of market mechanism highlights the sublation of monopoly and the advocation of competition. Under the constraint of financial budget, it is beneficial to reduce the cost of public service and relieve the government financial pressure by using the benefit analysis of output and changing the extensive mode of economic growth. Thirdly, using the non-governmental, professional and flexible advantages of social organizations to make up for the defects of the government's direct production, can better meet the public demand for heterogeneous and diversified public services, and help to improve public satisfaction. Finally, in the process of transfer to the social function of public service, the government gradually from the complicated social affairs pulled out, "while the government downsizing of the completion of the transformation from" direct producers "to" supervise "the role, by focusing on market guidance, performance evaluation and transformation of government functions to achieve. Finally, in the process of transfer to the social function of public service, the government gradually from the complicated social affairs pulled out, in the realization of "government downsizing" is also completed by the "direct producers" to "supervise" the role change, finally achieve the purpose of transformation of government functions.

\subsection{Based on the Perspective of Purchase Object: Linking Up With the Reform of Social Governance System and} Realizing the Self-Growth of Society

The interaction between government procurement of public services and social governance system innovation is obvious: Government procurement of public services drives social governance system reform and innovation, while social governance system innovation in turn provides organizational support for government procurement of public services. In recent years, with the government purchase of public service practice, the development trend of social organization is obvious, has improved in scale, influence, professional and public welfare, widely active in many fields of scientific research, education, health, culture, sports, social services, etc. According to statistics, as of the end of 2015, the number of social organizations nationwide is 0.66 million, the number will reach 0.88 million by 2020 , and will reach 1.73 million by 2030.At the same time, in view of the lack of social management system and the lack of participation in social organizations, the government clearly puts forward the innovative social governance system, and uses the participation of all sectors of society, especially through the self -management, self-service, self-education and self-discipline of the social organizations, to achieve the positive interaction between government governance and social autonomy.

\section{Risk Analysis of Government Purchasing Public Services}

Throughout the process of government purchase of public services, including public resources investment, public resources allocation and transformation, public service output and feedback and other links. Due to the different roles and core operating mechanisms of different links, the risks of government procurement of public services can be further subdivided into economic risk, market risk, social risk and management risk. In order to ensure the pertinence and effectiveness of risk prevention and management, it is necessary to make further analysis on the path and mechanism of risk generation. The detailed analysis is as follows:

\subsection{Economic Risk}

Economic risk refers to the deviation between the expected income and the actual income of the main body of the economic behavior in the market economy. In general, the economic risk has the characteristics of objectivity, randomness and ambiguity, implicative and strong destruction etc. In the context of government buying public service, from the perspective of economy, economic risk mainly refers to the failure of public resources input and insufficient input of public resources, cost saving and efficiency improvement. Government procurement of 
public services may gain economic benefits, mainly from the public service sector, open to private capital and public expenditure structure optimization of two aspects. In contrast, the "economic paradox" in practice is related to regional heterogeneity, public budget, internal effects, and power capital.

First, with the opening of the public resource allocation system, the conflict between the limitation of resources and the infinity of demand and the strong impulse of resource acquisition by the actors make any institutional arrangement likely to produce instrumentalism tendency. Secondly, according to the notice on the budget management of government procurement services, the funds required by the government to purchase services should be included in the budget, and adhere to the principle of "non-budget not implemented" and "budget after implementation" principle. However, in Chinese fiscal decentralization and political centralization system, due to the lack of budget budget mechanism, soft constraint, no budget constraint problem, public finance change as a strategic tool, the expenditure structure is distorted seriously. Thirdly, the "internal effect" emphasizes the self-interest and limited rationality of the government. Have greater discretion in the non-compulsory administration within the scope of the local government, in order to finance income and private income maximization, borrow "government purchase" in the name of misappropriating cash, forming an "organized irresponsibility" situation. Fourthly, when a large number of private capital enters the public service field, power is easily linked with capital. In the case of bureaucratic monopoly capital, enterprise capture of government and related party transactions, social welfare is to exploit and plunder and government procurement of public services has become a tool for a small number of people to seek private benefits. Finally, any institutional arrangement is not an abstract existence. Transaction costs are widespread and cannot disappear in government actions. Information cost, decision cost, negotiation cost, supervision cost and risk cost belong to the category of transaction cost. Due to the existence of transaction costs, the government purchase of public services may exceed the contract provisions, which is the key reason why the policy implementation is easy to encounter "ceiling".

\subsection{Market Risk}

In the market competition, the basic motivation and goal of competition is to achieve maximum income. However, the expected interests of the competitors are not always achieved. In fact, competition itself will also cause competitors to face the danger of failing to achieve their expected interest goals, even in economic interests. The possibility of deviating from the expected interests of the actual realization is the risk that the competitor faces is the market risk. Market risk is a more specific economic risk, but it is discussed from the perspective of the market. The government buys public service as a quasi-market which is led by the government, which aims to make use of the market to realize the efficient allocation of public resources. When public service transfers from hierarchical direct production to market-oriented institutional arrangement, the result is complex and multiple. In the context of government purchase of public services, market risks are mainly characterized by supply blindness, lack of supply, lack of publicity, external negative effects, etc., mainly related to quasi market mechanism, market access barriers, incomplete contracts and market defects.

First, the public service market is not the product of further evolution and subdivision of the free market, but a quasi-market between the bureaucracy and the free market. Compared with the free market, uncertainty and inadequate competition are the two major challenges. Access standard is one of the key factors that influence the market structure and competition level. As the country will develop social organizations into an important category of social governance innovation, social organizations in policy and institutional barriers gradually removed. However, behind the seemingly loose policy environment, social organizations encounter such barriers as "regulating formalism", "glass door" and "spring door". The inequality of competition opportunity weakens the competition and increases the rent-seeking corruption space. Thirdly, contract outsourcing is the dominant form of government procurement of public services. Because of the limited rationality, asymmetric information and complexity of transactions, the contract, which is used to restrict speculation or motivation, becomes incomplete contract. When there are loopholes or defects in management, this kind of incomplete is easy to induce opportunistic behavior, produce moral hazard and adverse selection. Finally, with the study of government purchasing services, it is found that the market does not always lead to cost savings, efficiency improvement and quality improvement. The market defect indicates that the market-oriented reform is bounded. Even if the market can realize the optimal allocation of resources, it cannot eliminate the public value crisis and the negative external effect.

\subsection{Social Risk}

Social risk is a possibility that leads to social conflicts, endangering social stability and social order, and more directly, social risk means the possibility of social crisis. At present, the social risk in China has many 
characteristics, such as multiple, diversity, simultaneity, diversity of risk sources, risk magnifying possibility, potential risk trend and so on. From the perspective of the social field, the government should not only achieve economic benefits such as cost saving and competitive efficiency, but also give consideration to social benefits such as social governance, public response, fairness and justice, etc. Is the essence of social relations and re adjust the public interest authority redistribution, the possibility of causing social disorder, conflicts and even social crisis. It is mainly related to the factors of institutional change, voluntary failure, social trust, cooperation mechanism, information disclosure and so on.

First of all, as a new institutional supply under the reform of public service system, government purchase of public services is a kind of institutional change which is implemented from top to bottom by government authority. The main limitations are as follows: on the one hand, when the institutional arrangement does not match the environment, the policy will distort or even fail; on the other hand, the institutional change is based on the reconstruction of interests, and the resistance and resistance of the aggrieved parties may lead to new social contradictions.

Secondly, voluntary organizations trapped in certain factors inside and outside the organization cannot effectively engage in voluntary service phenomenon is voluntary failure. Because of the advantages of organization, professionalism, non-profit, civil and voluntary, social organizations become the most important actors in the undertaking of public service. However, for a long time, due to social system, growth path, self-development and ideology, etc. The main position of social organizations and the lack of voluntary function are serious, and they can not effectively undertake social functions. It has become a short board of social cooperation governance. Thirdly, Social trust is not only a kind of psychological contract and social capital, but also a useful supplement to the formal system of social governance, and it can better maintain the governance network Lack of public service, weak market evaluation, bureaucratic system closure, government response and lack of public opinion management make the government and the public lack of positive interaction. In addition, recent failures in large purchases have seriously disrupted public confidence. Fourthly, from the perspective of social governance, "government procurement of public services" is achieved through the interaction and cooperation between the government and society to achieve the transfer and undertaking of public service functions. Although the prototype of cooperative governance network has already appeared, the relationship between network organization and synergy effect is not a simple linear relationship. The network organization not only has ability to produce synergistic effect, different goals, cooperation constraints, selection bias and resource dependence are likely to lead to "failure". Finally, information disclosure can effectively prevent the non-public application of public power, and ensure fair competition and informed supervision. According to the world trade organization to develop the "government procurement agreement", in the procurement of information release, the procurement notice, the participation conditions, supplier qualification, technical specifications, tender documents, term, negotiation, restricted electronic bidding, quotation, tender and contract award and other aspects of the information and requirements must be comprehensive and detailed publicity. But from the actual operation of our country, the information disclosure is obviously insufficient.

\subsection{Management Risk}

Management risk refers to the level of management in the process of management because of information asymmetry, poor management, misjudgment and so on. It is a subjective and human risk that management risk is embodied in every detail that constitutes the management system. From the specific administrative area, the government's purchase of public services is the process of the transfer of the functions of the government's public services to the society and the return of the supervisory function, which belongs to the category of the reform of the administrative system. In other words, only the government is responsible, "government procurement of public services" can be responsible. The government by direct payment to the guarantor does not mean escape the responsibility of the government in the field of public service, on the contrary, the government should take the administrative responsibility guarantee. Management risk is mainly related to the quality of managers, organizational structure, system construction and management process.

Firstly, the quality of administrators directly affects the government management ability. In practice, many government officials disagree with the government's purchase of public services, regard it as the tool of "political tournament" and "strategic arrangement of emotional concern"'". In addition, the high incidence of bribery, rent seeking, corruption and other issues have nothing to do with the quality of managers. Secondly, strengthening the construction of government management ability should strengthen the organization guarantee. At present, China's government purchase of public service management institutions are mainly functions department management, special committees, the respective functions of management and management combined with four modes, but the presence of repetition, lack of unified and professional, and the demand for public services do not 
match the problem, seriously affected the government purchases of public services unified deployment and supervision and management work. Thirdly, the system is the boundary, bottom line and basis of action. Although the practice of "government procurement of public services" has been practiced for more than ten years, it still faces the dilemma of "lack of policy and system". Lack of institutional supply, design defects, rigid operation, lack of repair capacity lead to the lack of legal support and necessary constraints for government procurement of public services. Fourthly, decision making ability is the core ability of modern government management. Lack of leadership, arbitrary manipulation and public participation is typical of our government decision-making ineffective. It is mainly related to the excessive concentration of administrative decision-making power and the excessive scope of discretion in china. One of the results of public service outsourcing is a decentralized decision making. In the process of creative administration, the government should grasp the attribute of freedom, and guard against the infinite extension of authority. Fifthly, do not want to abuse administrative power must accept supervision, which is law. The "weakening" and "virtual" of supervision make the supervision formalization, the subject of supervision dispersed, the scope of supervision limited, the supervision model rigid, and the responsibility not implemented. The government management falls into a kind of deadlock without internal restraint and external control, and the quality of public service cannot be guaranteed. Finally, the government performance evaluation is a kind of preventive risk filtering mechanism, although the government performance evaluation concept has been widely recognized in recent years, but the actual progress is relatively slow. On the one hand, the intangible, heterogeneous and perishable characteristics of the evaluation object make it difficult to obtain and evaluate the information. On the other hand, the problems such as formalization of assessment, serious internal control, and disconnection between evaluation and feedback restrict the effectiveness of performance evaluation mechanism.

\section{Risk Prevention and Control Path of Government Purchase of Public Services}

Based on the above analysis of risk factors, government procurement of public services can be carried out from the following aspects of risk prevention:

First, reasonable guide private capital into the public service field. The opening of public service field to private capital can realize the supplement of private capital to state-owned capital and the effective integration of social resources. However, because of the value conflict between the "profit seeking" of capital and the "publicity" of public service, government procurement of public services is easy to become a tool for a small number of bigwigs. Therefore, the reasonable guidance of private capital investment in the field of public services, the first is to establish and improve the power constraints mechanism, regulate self- interested behavior, to avoid excessive administrative power to encroach on the economic field, vigilance "aid hand" as "grab hand", to prevent "pseudo government purchase""'. The second is to reasonably guide the investment channels, methods, progress and quantity of private capital, reform the administrative examination and approval system, and give necessary policy support and tilt in finance, taxation, technology and other aspects. The third is to improve the ability of enterprise standardized management, especially to improve internal governance, financial transparency, information disclosure and credit system construction.

Second, improving government management to ensure the effective allocation of administrative power. Under the mode of government purchase of public service, the government bears the important task of social empowerment, market construction and public interest maintenance. It is the main body of risk responsibility and the main body of risk governance, and should play a leading and dominant role. Therefore, to improve the ability of government management, it is necessary to improve the supporting system, fill the gap of policy, and strengthen institutional constraints. Improve decision-making effectiveness, function authority accurate positioning, to avoid excessive concentration of decision-making power, standardize decision-making process. Improve the government performance evaluation system, establish an independent third party evaluation mechanism, pay attention to the feedback and application of the evaluation results. To avoid responsibility vacuum and management loopholes, the supervision and control function runs through the whole process of management, focusing on performance supervision and financial supervision, and adhering to the combination of pre, post and post control.

Third, enhance the ability of social autonomy and change the weak situation of society. In the process of the transfer of state power and responsibility to the society, the social organizations and the public are promoted to the main body of social cooperation governance, and assume the governance responsibility of sharing social space and sharing public affairs. To enhance social autonomy, the first is to clarify the boundaries of responsibilities and rectify the "offside" and "dislocation" of duty". In the boundary of public power activity, we should follow the principle of "doing something for something but not doing it". To cultivate and support the public service and social organization development as the focus, to enhance the social undertaking. To improve 
the management system of social organizations, remove institutional barriers, increase institutional supply, and strengthen evaluation and supervision. The second is to improve the social organization "internal ecology", enhance the ability of independent governance. The basic attribute of public service requires that social organizations should take public responsibility as their mission. To implement the independent management, perfect regulation, organization structure, resource management, financial management, evaluation mechanism and information disclosure of internal governance structure. To enhance the capital operation, broaden the channels of raising capital, enhanced made function. To manage the project strictly, strengthen the control of activities and performance feedback. Based on the law mechanism, achieve social legitimacy through professional services and public trust construction. The third is to establish social trust mechanism and increase social governance flexibility. Involve public participation in all aspects of public service production, delivery and feedback. Perfect the investigation and evaluation mechanism, communication mechanism and feedback mechanism. Strengthen the management of public opinion and enhance the government response ability. Paying attention to the cultivation of administrative ethics value and accumulating cognitive social capital. The four is to improve the information disclosure system, and actively promote "sunshine procurement". In line with the principle of timely and accurate, the government purchases public services public budget, budget implementation, purchase service content, purchase methods, purchase procedures, undertake the main body, contract content and performance evaluation and other related content regularly to the public disclosure.

\section{Fourth, give full play to the function of market mechanism to the allocation of public resources.}

The key of public service marketization is to realize the docking of market mechanism and public service: One is to perfect the market construction. We should straighten out the relationship of resource distribution, define the responsibility limit between the market subject and the government power, and give public power to the market which can be allocated to the market, and play the leading role of the government in the market failure. Drawing on the experience of western countries, sorting out the list of government purchases of public service lists, compiling guidelines for service items by item by item, specifying requirements, processes, model texts and time limits. Two is to regulate the market participation behavior. First of all, from the main production perspective, social organizations follow the basic rules of the market, adhere to the industry law, strict control of financial to efficiency and cost. To improve the contract negotiation, to provide quality services, full market demand and obtain consumer acceptance as the standard of competition. The production and business operation to public responsibility as a baseline, such as monopoly, skimming, capture, transfer of benefits, the government bribery conspiracy against the public interest should be strictly prohibited for. Secondly, from the perspective of the subject of consumption, the public should change the concept of consumption and guide the supply of the market. The public as a consumer of public services, is not passive. They can request the public service provider needs to respond quickly to influence the government for and decision. Choose through the service provider, service type and service content to stimulate market activity. Through satisfaction evaluation, to achieve the survival of the fittest supplier. With the change of the public service production main body, the public will pay attention to gradually transferred to the public service provider qualifications can, increase the provision of public services to the social identity, form a virtuous circle of public awareness, public experience, public supervision, public. Third is strict market control. The whole process of government supervision is an inescapable responsibility in the market operation. This responsibility includes strict supervision over the producer's public service cost, service quantity, service quality, service schedule and service effect. Specifically, in addition to the government to perform the basic management functions, but also to improve the supplier selection mechanism, to develop reasonable market access standards, especially to break administrative barriers and rigid barriers. Strengthening the ability of contract management, ensuring the completeness of contract preparation, the fairness of contract negotiation, and the effectiveness of contract execution. Emphasizing the value guidance, emphasizing the public value rationality rather than the instrumental rationality, and taking publicity as the keynote of the market-oriented operation of public services.

Fifth, Link up with the supporting reform and perfect the supply system of public service. Any reform of the system is not isolated. To avoid the risks of government, purchase of public services, besides the optimization of the system itself, it is necessary to coordinate with the supporting reforms to form a benign system operation environment. First of all, the government purchases public services into the scope of government procurement. This is also a more consistent view of the current academic circles. The government procurement of public services into government procurement has significant advantages: it can provide effective system and legal guarantee for the government to purchase public services. It is beneficial to supervise the government purchase of public services, and to innovate the government purchase service through the reference and transplantation of purchasing methods. Secondly, it should be compatible with the reform of public finance system. The funds 
needed by the government to purchase services are included in the budget, and the overall budget is arranged from the budget of the department or the approved special funds. Government procurement of public services under the support of public finance is conducive to the balance of demand and supply of public services, smoothing economic fluctuations and maintaining social fairness and justice. Thirdly, it should be connected with the reform of public institutions. Through the reform of government purchase service, the reform and transformation of public institutions should be supported, and the public service ability of public institutions will be enhanced. However, the convergence of government procurement services and institutional reform is a systematic project, which requires both the overall planning and coordination of the relevant departments, but also the transformation and upgrading of the management and service capabilities of institutions. Finally, the diversified supply mode should be implemented. With the change of the relationship between the state and society, the mixed supply will become the inevitable trend of the development of the public service supply system. As for the supply mode, we should consider the market production conditions, social cooperation environment, government management capacity and the quantity and specifications of public services, so as to match the supply mode choice with the social situation.

\section{References}

Dang, X. Y. (2013). Rebuild social trust: the spiritual journey of China's social construction. China Administration, (7), 60-65.

Guy, P. (2001). Government's future governance model. Renmin University of China Press.

Liu, X. C. (2008). Mechanism analysis and preventive measures of government procurement corruption. China Circulation Economy, 22(8), 8-11.

Lv, S. G. (2012). Government decentralization and civil relay. The people's daily, (13).

Ma, J. F. (2013). Multiple philanthropic cooperation and its legal regulation. Jiangxi Social Sciences, (9), $148-153$.

Xiang, X. S. (2012). Research on the setting up of government purchasing public service management organization. Journal of Fujian provincial Party School of CPC, (3), 41-47.

Zhang, M. (2015). Administration guarantee liability after government purchase of public services. Administrative Forum, (5), 64-68.

\section{Copyrights}

Copyright for this article is retained by the author(s), with first publication rights granted to the journal.

This is an open-access article distributed under the terms and conditions of the Creative Commons Attribution license (http://creativecommons.org/licenses/by/4.0/). 